\title{
Desbravando os horizontes do conhecimento: universalização e democratização do acesso
}

Estamos disponibilizando à comunidade científica mais um fascículo da Paideia, fruto de criterioso trabalho de seleção, aferição e aperfeiçoamento da qualidade dos manuscritos submetidos à avaliação.

A Paideia tem seguido à risca o compromisso que distingue sua linha editorial, ao se propor a dar guarida a artigos que efetivamente representam uma contribuição original às áreas do conhecimento em que se inserem. Nesse sentido, o processo editorial tem se pautado pelo rigor e imparcialidade com que conduzimos as decisões. Os critérios preponderantes para a análise e qualificação dos manuscritos submetidos à revista são a qualidade textual e a consistência da contribuição teórico-metodológica, reconhecida pelos pares a partir do procedimento de blind review. O objetivo é assegurar alto padrão de qualidade no julgamento dos artigos em avaliação.

Também temos conseguido abreviar, na medida do possível, o tempo de tramitação dos manuscritos, pois estamos cientes de que essa é uma das queixas mais recorrentes dos autores que submetem seus artigos e que, naturalmente, sentem-se ansiosos para receber um feedback dos periódicos. Este e outros avanços têm sido sistematicamente documentados nos Relatórios de Gestão que temos apresentado no primeiro fascículo de cada volume.

Para mantermos o que temos conquistado nos últimos anos e expandirmos a amplitude de nossos avanços, precisamos investir em estratégias de captação de recursos públicos que possam favorecer o equilíbrio financeiro de nossa revista. Nesse sentido, é preciso que os periódicos nacionais reúnam suas forças para ampliar nossa participação na formulação de Políticas Públicas, visando à alimentação e aprimoramento permanente do que temos produzido com perseverança e trabalho árduo, entendendo que as alternativas que vislumbramos devem ter um campo compartilhado no qual ganham sentido.

No mundo contemporâneo, nossas ações devem ter como horizonte a política de difusão ampla e aberta do patrimônio científico produzido no país. Em uma sociedade cada vez mais globalizada, universalizar o acesso à informação científica é um modo de consolidar a democratização do usufruto do conhecimento produzido pelo coletivo. Nessa vertente, nos últimos dois anos a Paideia não só corrigiu paulatinamente seu problema de periodicidade, como também ampliou o acervo de números anteriores, tornando-o disponível na SciELO. Temos orgulho de termos coordenado tarefa de tal envergadura, sobretudo porque cada vez mais se sedimenta o pressuposto de que o conhecimento científico, para existir, precisa estar disponível on line.
Considerando esse contexto, entregamos aos leitores o último número de 2009. Uma pluralidade de temas e abordagens metodológicas atravessam os artigos encartados no volume 19 número 44 da Paideia.

O presente fascículo é aberto com o estudo internacional Mudanças no self de carreira em estudantes universitários, assinado por Ana Daniela Silva, Maria do Céu Taveira e Eugénia Ribeiro, da Universidade do Minho, Portugal. As autoras investigam mudanças no "self de carreira" entre estudantes universitários do último ano da graduação e concluem que o término do curso enseja dificuldades no planejamento da carreira, revelando que o papel da universidade não se restringe à formação técnico-acadêmica do alunado, já que lhe cabe estimulá-lo a refletir sobre sua profissionalização e o contexto em que seu trabalho se insere.

A segunda contribuição corresponde ao artigo Moralidade e homicídio: um estudo sobre a ação do transgressor, de Luciana Souza Borges e Heloisa Moulin de Alencar, da Universidade Federal do Espírito Santo, investiga os juízos de representação da realidade e valor moral de 20 homens homicidas. Pautando-se nas formulações piagetianas sobre desenvolvimento moral, as pesquisadoras discutem os juízos morais de encarcerados e as representações que atribuem ao delito que cometeram. Trata-se de um estudo oportuno frente à complexidade do crescente fenômeno da criminalidade.

A seguir, o artigo $A$ adoção de crianças com necessidades especiais na perspectiva dos pais adotivos, de Célia Maria Souto Maior de Souza Fonsêca, Carina Pessoa Santos e Cristina Maria de Souza Brito Dias, da Universidade Católica de Pernambuco, aborda as percepções e vivências de pais adotivos de crianças portadoras de necessidades especiais, por meio da realização de entrevistas. As autoras consideram que, apesar das dificuldades e preconceitos enfrentados pelos participantes, eles também relatam momentos de satisfação.

Na sequência, o estudo Atividade de desenho como mediadora de interações sociais entre crianças, da autoria de Talita Pereira Dias e Nancy Vinagre Fonseca de Almeida, da Universidade Federal de São Carlos, analisa tipos de interações sociais que surgem entre crianças a partir de quatro situações de desenho diversas. Foram realizadas videogravações com crianças de uma creche, que evidenciaram que a atividade em questão promove diversos tipos de interações sociais, cuja quantidade e complexidade se eleva conforme o aumento da idade.

Prosseguindo as discussões no âmbito da Psicologia do Desenvolvimento, Desenvolvimento sociocognitivo e histórias infantis: subsidios para a prática docente, de Marisa 
Cosenza Rodrigues e Aline Lima Tavares, da Universidade Federal de Juiz de Fora, avalia a ocorrência de termos mentais em uma amostra de livros de histórias infantis nacionais, a partir das proposições da Teoria da Mente. As autoras concluem que o livro infantil constitui um instrumento valioso para a promoção do desenvolvimento sociocognitivo, reportando-nos ao papel da família e do Estado no incentivo à leitura como forma de expansão da compreensão do mundo.

$\mathrm{O}$ artigo Percepções de escolares com deficiência visual em relação ao seu processo de escolarização, de Edméa Rita Temporini e Newton Kara José, da Universidade de São Paulo, São Paulo, e Rita de Cassia Ietto Montilha, Maria Inês Rubo de Souza Nobre e Maria Elisabete Rodrigues Freire Gasparetto, da Universidade Estadual de Campinas, estuda as percepções de deficientes visuais em relação a seu processo de escolarização, a partir de questionário e entrevista. Os dados evidenciam que poucos alunos com deficiência visual estão inseridos no ensino regular do município em questão, bem como a importância que estes outorgam ao professor por ser o elemento humano com quem se relacionam diariamente via aprendizagem.

Dando continuidade ao debate sobre a inclusão de portadores de deficiência visual, o trabalho Habilidades cognitivo-linguísticas e segmentação lexical em braille, assinado por Clarissa de Arruda Nicolaiewsky e Jane Correa, da Universidade Federal do Rio de Janeiro, investiga a relação entre habilidades cognitivas e linguísticas e segmentação lexical na produção textual em braille de alunos matriculados no $1^{\circ}$ ciclo do ensino fundamental de uma instituição especializada no atendimento desta população. A partir do conceito de hipossegmentação e hipersegmentação e sua aplicabilidade para a pesquisa, as autoras concluem que fomentar práticas pedagógicas que promovam o treinamento de habilidades cognitivas e linguísticas facilitaria a aquisição do método braille.

A seguir, apresenta-se o artigo Percepção de faces em crianças e adolescentes com Transtorno Invasivo do Desenvolvimento, de Fernanda Tebexreni Orsati, da Syracuse University, EUA, e Tatiana Mecca, José Salomão Schwartzman e Elizeu Coutinho de Macedo, lotados na Universidade Presbiteriana Mackenzie. Os autores compararam a percepção de faces humanas entre crianças diagnosticadas com Transtorno Invasivo do Desenvolvimento (TID) e grupo controle, via rastreamento visual em determinada tarefa de percepção de faces, contribuindo para o debate sobre a percepção social de crianças acometidas por essa patologia.

$\mathrm{O}$ artigo seguinte Gênero, gerações e espaço doméstico: trabalho, casa e família, de Mara Coelho de Souza Lago, Carolina Duarte de Souza, Erikson Kaszubowski e Marina Silveira Soares, da Universidade Federal de Santa Catarina, contempla a subárea Sociologia da Família. Os pesquisadores realizaram um estudo sobre as relações de gênero no espaço doméstico a partir da análise das relações dos sujeitos com seus espaços de vida familiar, particularmente suas representações e valores sobre o trabalho doméstico. Pautando-se no método etnográfico, foram feitas entrevistas e videogravações. Os dados evidenciam que as marcas tradicionais de gênero persistem entre a população estudada, no entanto, a inserção das mulheres no mercado de trabalho e o processo de urbanização do município têm acarretado modificações paulatinas nas relações familiares e de sociabilidade.

$\mathrm{O}$ artigo Estratégias para criar no trabalho: proposição teórica e validação psicométrica de medida, de Melissa Machado de Moraes e Suzana Maria Valle Lima, da Universidade de Brasília, aborda os processos criativos em organizações, tema pouco pesquisado pela literatura brasileira da área. As autoras discutem teoricamente a questão e propõem a validação psicométrica de medida de estratégias para criar no trabalho. Os dados evidenciam a viabilidade da medida e sua aplicabilidade para o contexto organizacional.

A seguir, o artigo Psicoterapia de grupo em hospitaldia psiquiátrico, de Ana Celina Pires de Campos Guimarães, da Universidade do Sagrado Coração, e José Onildo Betioli Contel, da Universidade de São Paulo, Ribeirão Preto, discute o papel da psicoterapia grupal para pacientes de um serviço de saúde mental. Os autores apresentam os pacientes de um grupo terapêutico, os temas discutidos, a frequência das verbalizações e o manejo terapêutico das sessões, e apontam para a importância dessa terapêutica para a promoção da autonomia dos participantes.

Ainda no contexto da psicoterapia de grupo, desta feita em serviços de saúde em nível de atenção primária, o trabalho Oficinas de promoção de saúde: discutindo os dilemas do cotidiano de um grupo de agentes comunitárias de saúde, de Jacqueline Isaac Machado Brigagão e Roselane Gonçalves, da Escola de Artes, Ciências e Humanidades, Universidade de São Paulo, campus Leste, relata o desenvolvimento de oficinas de promoção de saúde em um grupo de agentes comunitárias de saúde. As autoras discutem os percalços do cotidiano dessas profissionais em virtude da tensão existente entre a estrutura da rede pública de saúde e realidade da população local, da qual também fazem parte.

Finalizando a seção dedicada aos artigos originais, contempla-se o trabalho Maternidade e colapso: consultas terapêuticas na gestação e pós-parto, de Tania Mara Marques Granato e Tania Maria José Aiello-Vaisberg, da Pontifícia Universidade Católica de Campinas. Pautadas nas propostas de Winnicott e em relatos de casos clínicos, as pesquisadoras discutem a formulação de que estados psíquicos primitivos são ensejados via maternidade.

A seção subsequente destina-se à nota técnica intitulada Elaboração de um recurso educativo para identificação e expressão de emoções, da autoria de Lucas Cordeiro Freitas, da Universidade Federal de São Carlos, e Regina Cavalcanti de Albuquerque Lemmi, da Universidade de São Paulo, São Paulo. Os autores propõem um recurso educativo a ser utilizado no treinamento de habilidades sociais para expressão de emoções, constituindo-se em uma alternativa relevante para a promoção do desenvolvimento infantil. 
A seção final dedica-se à resenha Transcendendo o enfoque de gênero no contexto da violência no casal, de Ana Claudia Nunes de Souza Wanderbroocke e Carmen Leontina Ojeda Ocampo More, da Universidade Federal de Santa Catarina. As pesquisadoras apresentam o livro Casais e violência: um enfoque além do gênero, de Leonor M. Cantera, publicado pela editora Dom Quixote.

Desejamos uma leitura profícua a todos.

Manoel Antônio dos Santos

Editor Responsável 